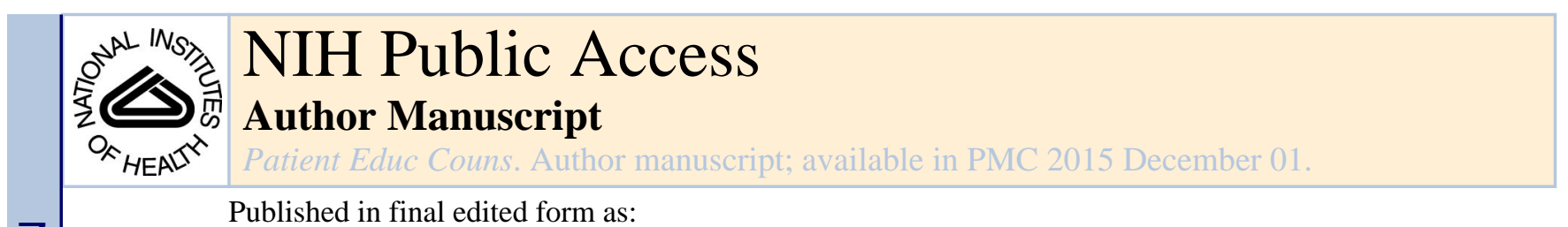

Published in final edited form as:

Patient Educ Couns. 2014 December ; 97(3): 327-331. doi:10.1016/j.pec.2014.09.009.

\title{
A Method to Determine the Impact of Patient-Centered Care Interventions in Primary Care
}

\author{
Timothy P. Daaleman, DO, MPH, \\ Department of Family Medicine, Cecil G. Sheps Center for Health Services Research, University \\ of North Carolina at Chapel Hill \\ Christopher M. Shea, PhD, \\ Department of Health Policy and Management, University of North Carolina at Chapel Hill \\ Jacqueline Halladay, MD, MPH, and \\ Department of Family Medicine, Cecil G. Sheps Center for Health Services Research, University \\ of North Carolina at Chapel Hill \\ David Reed, PhD \\ Cecil G. Sheps Center for Health Services Research, University of North Carolina at Chapel Hill
}

\begin{abstract}
INTRODUCTION-The implementation of patient-centered care (PCC) innovations continues to be poorly understood. We used the implementation effectiveness framework to pilot a method for measuring the impact of a PCC innovation in primary care practices.

METHODS-We analyzed data from a prior study that assessed the implementation of an electronic geriatric quality-of-life (QOL) module in 3 primary care practices in central North Carolina in 2011-12. Patients responded to the items and the subsequent patient-provider encounter was coded using the Roter Interaction Analysis System (RIAS) system. We developed an implementation effectiveness measure specific to the QOL module (i.e., frequency of usage during the encounter) using RIAS and then tested if there were differences with RIAS codes using analysis of variance.
\end{abstract}

RESULTS-A total of 60 patient-provider encounters examined differences in the uptake of the QOL module (i.e., implementation-effectiveness measure) with the frequency of RIAS codes during the encounter (i.e., patient-centeredness measure). There was a significant association between the effectiveness measure and patient-centered RIAS codes.

CONCLUSION-The concept of implementation effectiveness provided a useful framework determine the impact of a PCC innovation.

\footnotetext{
(C) 2014 Elsevier Ltd. All rights reserved.

Corresponding Author: Timothy P. Daaleman, DO, MPH, Department of Family Medicine, University of North Carolina at Chapel Hill, Campus Box 7595, Chapel Hill, NC 27514, 919-966-3899 (phone), 919-966-6125 (fax), tim_daaleman@ med.unc.edu.

Publisher's Disclaimer: This is a PDF file of an unedited manuscript that has been accepted for publication. As a service to our customers we are providing this early version of the manuscript. The manuscript will undergo copyediting, typesetting, and review of the resulting proof before it is published in its final citable form. Please note that during the production process errors may be discovered which could affect the content, and all legal disclaimers that apply to the journal pertain.
} 
PRACTICE IMPLICATIONS-A method that captures real-time interactions between patients and care staff over time can meaningfully evaluate PCC innovations.

\section{Keywords}

Implementation; methods; patient-centered care; primary care

\section{INTRODUCTION}

The Institute of Medicine (IOM) has identified patient centeredness as a core attribute of high quality care, on equal footing with safety, effectiveness, and equity. ${ }^{1}$ As a result, interventions for improving patient-centered care (PCC) at the organizational level continue to be developed, such as the Patient Centered Medical Home (PCMH), which has been envisioned as the predominant health care delivery model in the United States. ${ }^{2-4}$ Health care organizations often quickly adopt these and other complex ways of improving PCC but subsequently find that sustained change is challenging, time consuming, and costly. ${ }^{5}$ For example, although a Cochrane review concluded that PCC interventions are efficacious in improving care, ${ }^{6}$ findings of the National Demonstration Project showed that adoption of PCMH components resulted in only modest impact in areas such as chronic care outcomes, cost, and patient centeredness. ${ }^{7}$ These mixed results may reflect variation in methodologies that examined how effectively respective PCC interventions were implemented.

The recently established Patient Centered Outcomes Research Institute (PCORI) has identified implementation as a key barrier to the widespread adoption of potentially effective PCC interventions. ${ }^{8}$ PCORI will seek to develop and apply optimal methods that promote the sustained adoption of best PCC practices in health care settings. ${ }^{9}$ Yet implementation continues to be poorly understood and not well integrated into PCC research. Within clinical settings, implementation refers to initiatives that are intentionally designed to get the best practices, innovations, and/or associated products into routine and sustained use by providers and systems of care through designated adoption or organizational change interventions. ${ }^{10,11}$

Patient-centered care (PCC) was introduced by Balint and colleagues over 40 years ago to bring attention to the patient perspective in health care encounters. ${ }^{12}$ Since that time there have been methodological advances in measuring PCC, most notably the patient-centered clinical method developed by Levenstein and Stewart ${ }^{13,14}$ and the Picker/Commonwealth framework. ${ }^{15}$ A systematic review of over 3000 articles identified two well-validated PCC instruments. ${ }^{16}$ The first measure, the Patient Perception of Patient-Centeredness, was derived from empirical studies of the doctor-patient relationship and is based on the Stewart model. ${ }^{13,14}$ The Consultation Care Measure is the second measure and is also based on empirical studies of the doctor-patient relationship, Stewart's ${ }^{13}$ model, and patient interviews. ${ }^{17}$ More recently, the Consumer Assessment of Healthcare Providers and Systems (CAHPS) program added to the pool of PCC instruments by developing an expanded version of the Clinician \& Group 12-Month Survey that incorporates a Patient-Centered Medical Home Item Set. ${ }^{18}$ 
The National Demonstration Project (NDP) has also gauged patient centeredness by constructing a practice-level measure of the patient's assessment of PCMH. ${ }^{19}$ Finally, in a study of 21 primary care practices that achieved Level III recognition as medical homes by the National Committee for Quality Assurance, investigators utilized consumer choice satisfaction ratings (e.g., satisfaction with clinic, satisfaction with how well listened to) as the primary outcome measure of patient-centeredness. ${ }^{20}$ Although these have been noteworthy contributions to the development of methods to determine PCC outcomes, the growing body of research in this area has not produced a clear framework that guides robust measures of how well PCC interventions are adopted and implemented, and the subsequent impact on organizational processes.

In order to advance PCC, health care leaders and innovators need appropriate methods for gauging the impact of the complex interventions that they develop and implement. ${ }^{821}$ Since care interventions are embedded within organizational settings such as medical practices, meaningful approaches need to take into account how adoption and implementation are realized in real world clinical settings. ${ }^{22}$ Overcoming this obstacle first requires an approach that can gauge the effectiveness with which PCC interventions are implemented at the organizational level, ${ }^{21}$ thus allowing researchers and health care leaders to assess whether an efficacious PCC intervention was implemented successfully.

Implementation effectiveness is an organization-level construct that refers to the aggregated consistency, quality, and appropriateness of use of a specific innovation by intended users within an organization. ${ }^{23-25}$ Without a method for assessing implementation effectiveness, it will be difficult, if not impossible, to evaluate current implementation strategies or develop tailored evidence-based implementation strategies for organizations adopting PCC interventions. To address this need, we piloted a method for measuring the level of implementation effectiveness and the impact of PCC interventions in primary care. Specifically, we aimed to determine whether using the method was feasible and whether the results generated were consistent with a framework that predicts implementation effectiveness to be positively associated with the impact of an intervention.

\section{METHODS}

\section{Study Design}

We analyzed data from a prior feasibility study, described elsewhere, that assessed the implementation of a geriatric quality-of-life (QOL) module within 3 primary care practices in central North Carolina that had existing electronic health record systems. ${ }^{26}$ The module included seven health-related quality of life items related to physical health, emotional health, physical functioning and limitations in activities of daily living/instrumental activities of daily living, and level of social support. The QOL software was designed so that items would be prompted to appear within the electronic health record (EHR) during the intake portion of the medical encounter (i.e., when vital signs and chief complaints were recorded by clinical staff).

The parent study used a case study design and data were collected in 2011-12 via brief questionnaires and semi-structured interviews with providers, nursing/administrative staff, 
and patients nested within practices. We found that QOL modules must provide benefits, such as information that is specific enough to be useful and/or acted upon, that are substantial and prominent in order for physicians to decide that they are worthwhile and sustainable for implementation.

\section{Setting and Participants}

The setting and participants involved 3 primary care practices in central North Carolina that had operational electronic health record systems which could incorporate the QOL module. Two practices were small (i.e., fewer than 4 providers), independently owned family practices located in small towns, and the other was a general internal medicine practice that was part of a large academic health center. A research assistant (RA), with office nursing experience, was placed in the waiting room of the practice on designated data collection days to identify potentially eligible patients, invite participation, and seek informed consent. Since the parent study was a feasibility study, a goal 60 patient subjects, with approximately 20 from each practice site was targeted, and no re-enrollment was permitted. Patients who met the following criteria were eligible for the study: (1) age 50 years of age or older; (2) self-reported diagnosis of heart disease, lung disease, stroke, or cancer, and; (3) capable of speaking and reading English language. Specific exclusion criteria for the study included: (1) severe memory loss or impaired orientation, and; (2) acutely ill appearing. Participating patients received a $\$ 10$ gift card. The study was approved by the Institutional Review Board of the University of North Carolina at Chapel Hill.

\section{Data Collection and Analyses}

After informed consent was obtained, patients responded to the QOL items during the routine intake collection, recording of vital signs and chief complaint, which were entered into the electronic health record. The subsequent patient-provider encounter was recorded using a digital audio recorder. We coded the patient-provider audiotapes using the Roter Interaction Analysis System (RIAS), a widely recognized method of coding doctor-patient interactions. ${ }^{27,28}$ There are 4 main components to RIAS: (1) the coding approach is tailored to exchanges specific to the medical encounter and all patient and physician dialogue is coded into categories that may be applied to each speaker, although some categories may be more common to a particular speaker; (2) categories are tailored to directly reflect the content and context of the routine dialogue between patients and doctors during medical exchanges; (3) identification and classification of verbal events are coded directly from videotapes or audiotapes and not transcripts; (4) since coding is done directly from video or audiotapes, rather than transcripts, assessment of the tonal qualities of interaction is possible. $^{27,29}$

There are multiple RIAS categories that can be used and general RIAS categories include socio-emotional exchange (e.g., empathy and partnership statements, shows concern or worry), task-focused exchange (e.g., asks open or closed ended questions, gives information related to psychosocial concerns), and global affective ratings, or the affect or emotional context of the dialogue. ${ }^{2730}$ In RIAS, coding is tailored to exchanges specific to the medical encounter in which categories directly reflect the content and context of routine dialogue during medical exchanges. 2730

Patient Educ Couns. Author manuscript; available in PMC 2015 December 01. 
To measure implementation effectiveness, we developed a measure specific to the QOL module (i.e., frequency of QOL module usage noted during the encounter) using selected RIAS $^{26}$ categories which captured if the innovation was used consistently and appropriately by the intended user. We then tested if the implementation effectiveness measure was associated with several patient-centered RIAS categories by using analysis of variance with post hoc pairwise comparisons.

\section{RESULTS}

Table 1 presents the study eligibility and participation percentages, as well as reasons for refusal. For patients, there was a $13 \%$ refusal rate and the main reason for ineligibility was age. The providers who participated in the study averaged 52 years of age and half of the participants were female. Table 2 depicts the demographic characteristics of study patients and providers. A majority of providers (80\%) were board certified with an average of 21 years of experience. Just over one-half of the patients who participated were female and the average age was nearly 70 . The majority of the patients were Caucasian, with $43 \%$ being African American or Native American. Only one-quarter reported being in excellent or very good health, while over one-third reported being in fair or poor health.

A total of 60 patient-provider encounters were analyzed and Table 3 displays the differences between groups regarding the uptake of the QOL module (i.e., implementation-effectiveness measure) with the frequency of RIAS codes during the encounter (i.e., patient-centeredness measure). Uptake was operationalized as any reference either to any of the QOL questions or to prompts that were initiated by the computer during the encounter, while high uptake denoted a reference to both the QOL questions and computer prompts. We found that the implementation effectiveness (i.e., frequency of QOL module usage noted during a patientprovider encounter) of the QOL module was significantly associated with enhanced scores on patient-centered RIAS codes. ${ }^{26}$ For example, the mean for No Uptake (i.e., no reference to any QOL questions or prompts during encounter) was significantly lower (36.05) from the mean for High Uptake (74.14) for the RIAS code of positive rapport building. Although preliminary, we found that our method of data collection was feasible in real-world practice settings and that our results support an implementation effectiveness framework that can be used to determine the impact of patient-centered care interventions in primary care.

\section{DISCUSSION AND CONCLUSION}

Conceptually, implementation can be thought of as the period during which intended users of an innovation become skillful in using the innovation, such as a new care pathway or protocol. ${ }^{23}$ Evaluating the implementation process requires measuring how well the innovation is delivered or used. Implementation fidelity commonly refers to the degree to which a program is delivered as its developers intended however it has been operationalized in various ways, sometimes narrowly with measures of only a subset of fidelity elements, most frequently as process compliance. ${ }^{31,32}$ In contrast, implementation effectiveness emphasizes the consistency of innovation usage by members of an organization. ${ }^{23-25}$ Consistency refers to a lack of variation in level of use of the innovation by an individual targeted user within the organization over time and between individual targeted users within 
the organization. ${ }^{31,33}$ Therefore, evaluating consistency requires measuring use by all targeted users over a specified period of time.

In the present study, we drew from the implementation effectiveness framework to develop a method that used a robust, validated approach that captures patient-provider encounters (i.e., RIAS) in order to gauge the impact of a patient-centered intervention (i.e., the QOL module) in primary care practices. Our findings are consistent with expected differences between categories of implementation effectiveness of the QOL module and aspects of patient centeredness, as measured by RIAS interactions. To our knowledge, this is the first report of a conceptual or framework-based strategy to determine the impact of a patientcentered care intervention within primary care settings.

There were several limitations to the study. Although we met our patient recruitment goals and had a low refusal rate, our sample size was modest. In addition, our analyses of patientprovider encounters did not account for individual-level factors which influence communication dynamics in outpatient settings, such as provider characteristics. Finally, while we were able to code audio data of provider-patient communication to assess the level of the QOL module usage, we were not able to directly observe how the provider accessed the module during the encounter. Differences in how providers incorporated the module into their workflow may have affected their assessment of the value of its information.

\section{Practice Implications}

To further test and refine this proposed method, and authentically engage in a patient centered methodology, we suggest three strategies to advance the field. First, stakeholders, such as patients, physicians, and care support staff, need to be engaged at the developmental phase and throughout implementation, in order to define the appropriateness (e.g., was the innovation used in the expected manner?), consistency (e.g., was it used comparably?), and quality (e.g., did it add value?) of the care innovation. This can be done via focus groups and other qualitative approaches to help identify organizational and contextual factors that facilitate or impede meaningful and purposeful innovation implementation and measurement. ${ }^{34}$

Next, data collection and analytic strategies measuring implementation and impact need to go beyond the simple assessment of process and performance compliance, such as via checklists and other self-reporting strategies, in order to account for organizational-level factors. ${ }^{22}$ The use of video or audio interviews that capture real-time encounters between patients and members of the care team that they interact with (e.g., physicians, nursing, administrative and support staff) provides a potentially powerful approach. ${ }^{30,35}$ The Roter Interaction Analysis System (RIAS), used in the present study for example, is a widely recognized method of coding doctor-patient interactions that has the capacity to gauge the organizational-level impact of patient-centered care. ${ }^{27}$ In RIAS, coding is tailored to exchanges specific to the medical encounter into categories that directly reflect the content and context of the routine dialogue during medical exchanges. ${ }^{27}$

Finally, impact needs to be determined over time since it cannot be assumed that measuring implementation at single, discrete points will be predictive of sustained implementation. ${ }^{22}$ 
Longitudinal assessments at key intervals, using selected encounter-based audio or video interviews, can be critical to verifying that care innovations are successfully adopted at the organizational level, and to gauge the ongoing impact on important patient outcomes. In addition, assessments of impact over time provide opportunities for organizational learning, a process by which organizations make adaptations to the innovation which allow greater fit to the local environment. ${ }^{22}$

\section{Conclusion}

In summary, although patient-centered care interventions continue to be developed, determining the impact of these interventions within and across primary care settings remains challenging. ${ }^{8}$ The concept of implementation effectiveness provides a useful framework to gauge impact at the organizational level. ${ }^{21}$ And by employing a method that captures real-time interactions between patients and care staff over time, emerging PCC interventions can be more meaningfully evaluated.

\section{Acknowledgments}

Funding Support: National Institute on Aging (R21AG030166) NIH Clinical and Translational Science Awards (CTSA) (UL1TR000083) (KL2TR000084)

\section{References}

1. Institute of Medicine, Committee on Quality of Health Care in America. Crossing the Quality Chasm: A New Health System for the 21st Century. Washington DC: National Academy Press; 2001.

2. Landon BE, Gill JM, Antonelli RC, Rich EC. Prospects for rebuilding primary care using the patient-centered medical home. Health Affairs. 2010; 29:827-834. [PubMed: 20439868]

3. Berwick DM, Nolan TW, Whittington J. The triple aim: care, health, and cost. Health Affairs. 2008; 27:759-769. [PubMed: 18474969]

4. Rosenthal TC. The medical home: growing evidence to support a new approach to primary care. Journal of the American Board of Family Medicine. 2008; 21:427-440. [PubMed: 18772297]

5. Jaén CR, Crabtree BF, Palmer PJ, et al. Methods for evaluating practice change toward a patientcentered medical home. Annals of Family Medicine. 2010; 8:s9-s20. [PubMed: 20530398]

6. Lewin S, Skea Z, Entwistle VA, et al. Interventions for providers to promote a patient-centered approach in clinical consultations. Cochrane Database of Systematic Reviews. 2001:CD003267(4). 10.1002/14651858.CD003267 [PubMed: 11687181]

7. Jaén CR, Ferrer RL, Miller WL, et al. Patient outcomes at 26 months in the patient-centered medical home National Demonstration Project. Annals of Family Medicine. 2010; 8(Suppl 1):S57-S67. [PubMed: 20530395]

8. Methodology Committee of the Patient-Centered Outcomes Research Institute (PCORI). Methodological standards and patient-centeredness in comparative effectiveness research. Journal of the American Medical Association. 2012; 307:1636-1640. [PubMed: 22511692]

9. PCORI Methodology Committee. Draft Methodology Report: “Our Questions, Our Decisions: Standards for Patient-Centered Outcomes Research”. Washington, DC: Patient-Centered Outcomes Research Insititute; 2012.

10. Stetler CB, Mittman BS, Francis J. Overview of the VA Quality Enhancement Research Initiative (QUERI) and QUERI Theme Articles: QUERI Series. Implementation Science. 2008; 3:8. [PubMed: 18279503]

11. Curran GM, Bauer M, Mittman BS, Pyne JM, Stetler CB. Effectiveness-implementation hybrid designs. Medical Care. 2012; 50:217-226. [PubMed: 22310560] 
12. Balint, M.; Hunt, J.; Joyce, D., et al. Treatment or diagnosis: a study of repeat prescriptions in general practice. Philadelphia: J.B. Lippincott; 1970.

13. Stewart, M.; Brown, JB.; Weston, WW.; McWhinney, I.; McWilliam, CL.; Freeman, TR. Patientcentered medicine, transforming the clinical method. Thousand Oaks, CA: Sage; 1995.

14. Stewart M, Brown JB, Donner A, et al. The impact of patient-centered care on outcomes. Journal of Family Practice. 2000; 49:796-804. [PubMed: 11032203]

15. Gerteis, M.; Edgman-Levitan, S.; Daley, J.; Delbanco, TL. Through the patient's eyes, understanding and promoting patient-centered care. San Francisco: Jossey Bass; 1993.

16. Hudon C, Fortin M, Haggerty JL, Lambert M, Poitras M-E. Measuring Patients' Perceptions of Patient-Centered Care: A Systematic Review of Tools for Family Medicine. Annals of Family Medicine. 2011; 9:155-164. [PubMed: 21403143]

17. Little P, Everitt H, IW, et al. Observational study of effect of patient centredness and positive approach on outcomes of general practice consultations. British Medical Journal. 2001; 323:908911. [PubMed: 11668137]

18. Agency for Healthcare Research and Quality. [Accessed November 17, 2011] CAHPS PatientCentered Medical Home (PCMH) Item Set. 2011. http://www.cahps.ahrq.gov/Surveys-Guidance/ Item-Sets/PCMH.aspx

19. Nutting PA, Crabtree BF, Stewart EE, et al. Effect of facilitation on practice outcomes in the National Demonstration Project model of the patient-centered medical home. Annals of Family Medicine. 2010; 8:s33-s44. [PubMed: 20530393]

20. Solberg LI, Asche SE, Fontaine P, et al. Trends in quality during medical home transformation. Annals of Family Medicine. 2011; 9:515-521. [PubMed: 22084262]

21. Atkins D, Kupersmith J. Implementation research: a critical component of realizing the benefits of comparative effectiveness research. American Journal of Medicine. 2010; 123:e38-e45. [PubMed: 21184866]

22. Alexander JA, Hearld LR. Methods and metrics challenges of delivery-systems research. Implementation Science. 2012; 7:15. [PubMed: 22409885]

23. Klein KJ, Sorra JS. The challenge of implementation. Academy of Management Review. 1996; 21:1055-1080.

24. Klein KJ, Conn AB, Sorra JS. Implementing computerized technology: an organizational analysis. Journal of Applied Psychology. 2001; 86:811-824. [PubMed: 11596799]

25. Holahan PJ, et al. Implementing computer technology: a multi-organizational test of Klein and Sorra's model. Journal of Engineering and Technology Adaptation. 2004; 21:31-50.

26. Shea CM, Halladay J, Reed D, Daaleman TP. Integrating a health-related quality-of-life module within electronic health records: a comparative case study of assessing value added. BMC Health Serv Res. 2012; 12:67.10.1186/1472-6963-1112-1167 [PubMed: 22429407]

27. Roter, DL.; Larson, S. [Accessed 1-29-07] RIAS: The Roter Interaction Analysis System. 2006. http://www.rias.org/index

28. Roter DL, Larson S. The Roter interaction analysis system (RIAS): utility and flexibility for analysis of medical interactions. Patient Educ Couns. 2002; 46(4):243-251. [PubMed: 11932123]

29. Roter DL, Stewart M, Putnam SM, et al. Communication patterns of primary care physicians. Journal of the American Medical Association. 1997; 277:350-356. [PubMed: 9002500]

30. Roter DL, Stewart M, Putnam S, et al. Communication patterns of primary care physicians. Journal of the American Medical Association. 1997; 270:350-355. [PubMed: 9002500]

31. Bosworth HB, Almirall D, Weiner BJ, et al. The implementation of a translational study involving a primary care based behavioral program to improve blood pressure control: the HTN-IMPROVE study protocol. Implementation Science. 2010; 5:54. [PubMed: 20637095]

32. Helfrich CD, Damschroder LJ, Hagedorn HJ, et al. A critical synthesis of literature on the promoting action on research implementation in health services (PARIHS) framework. Implementation Science. 2010; 5:82. [PubMed: 20973988]

33. Damschroder LJ, Aron DC, Keith RE, et al. Fostering implementation of health services research findings into practice: a consolidated framework for advancing implementation science. Implementation Science. 2009; 4:50. [PubMed: 19664226] 
34. Creswell, JW.; Klassen, AC.; Clark, VLP.; Smith, KC. Best practices for mixed methods, research in the health sciences. Office of Behavioral and Social Science Research; 2011.

35. Henry SG, Fetters MD. Video elicitation interviews: a qualitative research method for investigating physician-patient interactions. Annals of Family Medicine. 2012; 10:118-125. [PubMed:

22412003] 


\section{Highlight}

- Health care leaders and innovators need appropriate methods for gauging the impact of the patient-centered care interventions that they develop and implement, taking into account how adoption and implementation are realized in real world clinical settings.

- Implementation effectiveness is an organization-level construct that refers to the aggregated consistency, quality, and appropriateness of use of a specific innovation by intended users within an organization.

- An implementation effectiveness framework that incorporates real-time patient encounters can meaningfully gauge the impact of a patient-centered intervention in primary care practices.

- To advance this approach, stakeholders need to be engaged at the developmental phase and throughout implementation, data acquisition should go beyond the simple assessment of process and performance compliance, and impact needs to be determined over a longitudinal period. 


\section{Table 1}

Study Eligibility, Refusal, and Enrollment

\begin{tabular}{|ll|}
\hline Characteristic & No. $(\%)$ \\
\hline Patients who presented for care while RA was on site: & 240 \\
\hline Eligible for QOL module: & $70(29.1 \%)$ \\
\hline Refused & $9(13.0 \%)$ \\
\hline Not approached due to RA interviewing another subject & $1(1.4 \%)$ \\
\hline Ineligible: & $170(70.8 \%)$ \\
\hline Acutely ill & $2(0.8 \%)$ \\
\hline Cognitive impairment & $6(2.5 \%)$ \\
\hline No inclusion Diagnosis & $65(27.1 \%)$ \\
\hline Under age 50 & $96(41.7 \%)$ \\
\hline Not English-speaking & $1(0.4 \%)$ \\
\hline
\end{tabular}




\section{Table 2}

\section{Characteristics of Study Participants}

\begin{tabular}{|c|c|}
\hline Provider characteristics & No. $(\%)$ or Mean (SD) \\
\hline Age & $50.4(6.7)$ \\
\hline Female & $3(60 \%)$ \\
\hline \multicolumn{2}{|l|}{ Race } \\
\hline White/Caucasian & $4(80 \%)$ \\
\hline Black/African American & $1(20 \%)$ \\
\hline Hispanic/Latino(a) & $0(0)$ \\
\hline Family Medicine & $3(60 \%)$ \\
\hline Internal Medicine & $2(40 \%)$ \\
\hline Board certified & $4(80 \%)$ \\
\hline Number of years certified & $21.0(4.4)$ \\
\hline \multicolumn{2}{|l|}{ Patient characteristics } \\
\hline Age & $69.6(11.9)$ \\
\hline Female & $32(56 \%)$ \\
\hline \multicolumn{2}{|l|}{ Race } \\
\hline White/Caucasian & $33(57 \%)$ \\
\hline Black/African American & $20(36 \%)$ \\
\hline American Indian & $4(7 \%)$ \\
\hline Hispanic/Latino(a) & $2(3 \%)$ \\
\hline \multicolumn{2}{|l|}{ Marital status } \\
\hline Single & $6(10 \%)$ \\
\hline Married & $32(56 \%)$ \\
\hline Widowed & $10(18 \%)$ \\
\hline Separated/Divorced & $9(16 \%)$ \\
\hline \multicolumn{2}{|l|}{ Education } \\
\hline Some high school or less & $23(40 \%)$ \\
\hline High school graduation & $14(25 \%)$ \\
\hline At least some college & $20(35 \%)$ \\
\hline \multicolumn{2}{|l|}{ Self-perceived health } \\
\hline Excellent/Very good & $15(26 \%)$ \\
\hline Good & $21(37 \%)$ \\
\hline Fair/Poor & $21(37 \%)$ \\
\hline \multicolumn{2}{|c|}{ Self-reported chronic conditions* } \\
\hline Heart disease & $31(54 \%)$ \\
\hline Lung disease & $18(32 \%)$ \\
\hline Cancer & $5(9 \%)$ \\
\hline Stroke-related condition & $8(14 \%)$ \\
\hline
\end{tabular}

Patient Educ Couns. Author manuscript; available in PMC 2015 December 01. 
* May have more than one condition 


\section{Table 3}

Analysis of Mean Differences in the Quality of Life Module Uptake (implementation-effectiveness measure) with Frequency of RIAS Codes (measures reflecting patient-centeredness) ( $\mathrm{N}=60$ patient-provider encounters)

\begin{tabular}{|l|l|l|l|l|}
\hline RIAS Code Frequency & No Uptake (Mean, SD) & Uptake (Mean, SD) & High Uptake (Mean, SD) & p-value* \\
\hline Emotional rapport building & $14.10(7.65)$ & $16.25(7.99)$ & $23.85(7.58)$ & 0.011 \\
\hline Facilitation and patient activation & $40.33(24.29)$ & $67.50(22.77)$ & $55.86(46.05)$ & 0.011 \\
\hline Procedural building & $33.67(18.14)$ & $48.50(15.28)$ & $53.86(21.65)$ & 0.009 \\
\hline Positive rapport building & $36.05(23.13)$ & $59.25(31.88)$ & $74.14(31.68)$ & 0.001 \\
\hline
\end{tabular}

* P value is for the overall test for differences among the means of the three uptake categories. Pairwise comparisons indicate a statistically significant difference between the means for the No uptake category compared to the High uptake category for three measures--Emotional rapport building, Procedural building, and Positive rapport building — and a difference between the means for No uptake compared to Uptake for Facilitation and Patient Activation. 